\title{
Does Lean healthcare improve patient satisfaction?: A mixed-method investigation into primary care
}

Bozena Bonnie Poksinska, Malgorzata Fialkowska-Filipek and Jon Engström

\section{Linköping University Post Print}

\section{Tweet}

N.B.: When citing this work, cite the original article.

Original Publication:

Bozena Bonnie Poksinska, Malgorzata Fialkowska-Filipek and Jon Engström, Does Lean healthcare improve patient satisfaction?: A mixed-method investigation into primary care, 2016, BMJ Quality and Safety.

http://dx.doi.org/10.1136/bmjqs-2015-004290

Copyright: BMJ Publishing Group

http://group.bmj.com/

Postprint available at: Linköping University Electronic Press

http://urn.kb.se/resolve?urn=urn:nbn:se:liu:diva-126610 


\title{
DOES LEAN HEALTHCARE IMPROVE PATIENT SATISFACTION? A MIXED-METHOD INVESTIGATION INTO PRIMARY CARE
}

\author{
Bozena Bonnie Poksinska ${ }^{1}$, Malgorzata Fialkowska-Filipek ${ }^{1,2}$ and Jon Engström ${ }^{1}$ \\ ${ }^{1}$ Quality Technology and Management, Department of Management and Engineering, Linköping \\ University, Linköping, Sweden \\ ${ }^{2}$ Department of Computer Science and Management, Wroclaw University of Technology, \\ Wroclaw, Poland
}

\begin{abstract}
Background - Lean healthcare is claimed to contribute to improved patient satisfaction, but there is limited evidence to support this notion. This study investigates how primary care centres working with Lean define and improve value from the patient's perspective, and how the application of Lean healthcare influences patient satisfaction.

Methods - This paper contains two qualitative case studies and a quantitative study based on results from the Swedish National Patient Survey. Through the case studies, we investigated how primary care organisations realised the principle of defining and improving value from the patient's perspective. In the quantitative study, we compared results from the patient satisfaction survey for 23 primary care centres working with Lean with a control group of 23 care centres not working with Lean. We also analysed changes in patient satisfaction over time.

Results - Our case studies reveal that Lean healthcare implementations primarily target efficiency and little attention is paid to the patient's perspective. The quantitative study shows no significantly better results in patient satisfaction for primary care centres working with Lean healthcare compared to those not working with Lean. Further, care centres working with Lean show no significant improvements in patient satisfaction over time.

Conclusions -Lean healthcare implementations seem to have a limited impact on improving patient satisfaction. Care providers need to pay more attention to integrating the patient's perspective in the application of Lean healthcare. Value needs to be defined and value streams need to be improved based on both the knowledge and clinical expertise of care providers, and the preferences and needs of patients.
\end{abstract}

Keywords - Lean healthcare, patient satisfaction, primary care

\section{Contact information to corresponding author:}

Bozena Bonnie Poksinska

Quality Technology and Management, Department of Management and Engineering, Linköping University, Linköping, Sweden

Email: bonnie.poksinska@liu.se

Phone: +4613282724 


\section{INTRODUCTION}

In recent years, there has been increased interest in improving healthcare services and a trend towards more patient-centred care. Lean production, which has roots in the automotive industry, has had an important impact on industrial practices, with success stories on improved productivity and quality. ${ }^{1}$ In the hope of achieving similar results, many healthcare organisations worldwide view Lean production as a way to improve efficiency, quality and responsiveness in order to meet patient needs..$^{2-4}$ Publications on Lean healthcare promise that it helps to improve patient satisfaction in several ways: it will help to pursue "the perfect patient experience" 56 " "increase value"7 and "improve quality and patient safety" 8 . However, there is little evidence that implementing Lean healthcare leads to increased patient satisfaction. The results from different case studies are encouraging, but mostly show outcomes reported from the healthcare organisation's perspective, such as increased patient throughput, reduced costs, and shorter waiting times. ${ }^{9}{ }^{10}$ To address this gap, we conducted qualitative case studies on how value is defined and improved in Lean healthcare, and quantitatively compared patient satisfaction in primary care centres working with Lean with those not working with Lean. In the following section, we introduce the concept of Lean healthcare. We also briefly highlight some concerns on the application of production-oriented models in services raised by contemporary service management research.

\section{LEAN HEALTHCARE}

Lean production has its roots in the Toyota Production System, which was considered "lean" since it required fewer resources to make a greater variety of products with fewer defects. ${ }^{11}$ Lean production is commonly described by five Lean principles: define value by the ultimate customer, map the value stream, create flow, establish pull and seek perfection. ${ }^{12}$ Defining value and mapping the value stream is the starting point to identify and eliminate non-value activities (waste) and enhance those that do add value, thus increasing value to customers. ${ }^{12}$ The Lean production literature, however, seldom discusses how to define value from the customer's perspective. In many cases, value is simply defined in opposition to waste: "What is not waste, is value."

Womack and Jones ${ }^{12}$ were among the first authors to suggest that Lean production could be applied to healthcare, arguing that the first step in its implementation would be developing care processes based on the patient's perspective, with a focus on shortening lead times and increasing value. Lean principles, such as value-stream orientation and crossfunctional teams, have been emphasised as especially relevant for the healthcare context. ${ }^{12}$ Lean healthcare is often described as a process improvement approach with a focus on identifying and eliminating waste from healthcare delivery processes. ${ }^{10}{ }^{13}$ Lean healthcare implementations typically start with mapping and analysing patient flows to identify delays, waiting times, repeated visits, errors and inappropriate procedures. ${ }^{14}{ }^{15}$ The most frequently applied Lean tool is Value Stream Mapping (VSM), which is used to expose problems and motivate staff to solve them through continuous improvement activities. ${ }^{10}$ Other Lean tools frequently applied in healthcare are standardised work, 5S (method for organizing the work place with 5 steps: Sorting, Setting in order, Systematic cleaning, Standardizing, and Sustaining), visual management, root-cause analysis and rapid improvement events. ${ }^{3}{ }^{16}$ The literature review also suggests that Lean healthcare is about turning employees into problem solvers that take ownership of improvement activities and work every day to streamline processes. ${ }^{781718}$ 


\section{POTENTIAL LIMITATIONS OF LEAN HEALTHCARE}

A vital question is whether Lean production, with its automotive industry roots, is appropriate for a complex service system such as healthcare. Lean production originates from the production of goods, and represents a goods-dominant logic (GDL). ${ }^{19}$ In GDL, the value of the product is inherent in it and the customer is a passive consumer of products. Today's service research instead suggests a move towards a service-dominant logic (SDL), in which the role of the customer in value creation is highlighted and value is perceived as individually experienced. ${ }^{19}{ }^{20}$ In this view, taking the example from the automotive industry, the value of the car is only potential before the customer actually obtains any benefit from it. The value is always co-created in the interaction between supplier and customer, with the supplier as the facilitator of this process. ${ }^{21}$ The customer value depends both on what is delivered (technical quality) and how service is delivered (functional quality). ${ }^{22}$

In the service management view, improving patient satisfaction requires understanding both interaction between the healthcare provider and the patient, and the patient's own value creation actions, which typically take place outside the walls of the care provider (for example, at the patient's home $)^{22 a}$. While this point of view is visible in healthcare in concepts such as the chronic care model, ${ }^{23}$ the patient empowerment movement and shared decisionmaking, ${ }^{24}$ it is not explicitly part of Lean healthcare. The research questions which this paper aims to answer, therefore, are by what means the central idea of Lean healthcare, that is, "defining value from the patient's perspective", is realised, and how the application of Lean healthcare influences patient satisfaction.

\section{METHODS}

Using a mixed methods strategy, we carried out qualitative case studies and analysed quantitative data from the Swedish National Patient Survey (NPS). We decided to focus only on primary care centres, since their nationally imposed prerequisites, structures and operations make them more uniform compared to specialised care. The primary care centres treat the most common illnesses that do not require hospitalisation, and are usually responsible for children, prenatal and rehabilitation care. The care is primarily given by the general practitioners (GPs) that mostly specialise in family medicine.

\section{Case studies}

We decided to study primary care centres that were considered as successful cases of Lean implementation in Sweden. The selection criteria were: at least five years of experience with Lean; and, documented evidence of improvements. The case organisations are considered the first primary care centres implementing Lean in Sweden and have been acclaimed in the press and public, with invitations to conferences and educational events. Given that only two cases were studied, the qualitative study has a limited generalisability. However, the cases complement the quantitative study as they show Lean principles in practice in the Swedish healthcare context.

We collected data through interviews $(n=15)$ and reviews of documents. ${ }^{25}$ The interviews were semi-structured and took about one to two hours depending on the interviewee. The interview questions focused on four main areas: definition of Lean healthcare; tools and techniques implemented; improvement work organisation; and results achieved. The interviewees were chosen to represent different professions and positions and the interviews were conducted until reaching the data saturation point (see Table I). All interviews were taped and transcribed. The document reviews included strategy documents, activity reports, handling plans, documented procedures, and performance data from past and ongoing Lean activities. 
We analysed the collected data, i.e. interview material and documents, using qualitative content analysis. ${ }^{26}$ Using the existing theory on Lean, the analysis started by identifying key concepts as initial coding categories related to the practices of defining and improving value from the patient's perspective. Three researchers independently coded the data and then jointly discussed the results to establish code content consensus.

A draft summary of the principal findings was presented at feedback sessions with key respondents. The purpose of these sessions was to validate the results and to expand the analysis through elaboration, reaction and the development of alternate and multiple interpretations of the findings. ${ }^{27}$

Table I: Case organisations

\begin{tabular}{|l|l|l|}
\hline Case & Description & Data collection \\
\hline $\begin{array}{l}\text { Care Centre } \\
\text { Alpha }\end{array}$ & $\begin{array}{l}\text { Primary care centre with } \\
\text { approx. 25 employees }\end{array}$ & $\begin{array}{l}\text { Interviews n=7 (care centre manager-physician, } \\
\text { two physicians, three nurses, one administrator) } \\
\text { Document review }\end{array}$ \\
\hline $\begin{array}{l}\text { Care Centre } \\
\text { Beta }\end{array}$ & $\begin{array}{l}\text { Primary care centre with } \\
\text { approx. 35 employees }\end{array}$ & $\begin{array}{l}\text { Interview n=8 (care centre manager - physiotherapist, } \\
\text { four physicians, two nurses, secretary) } \\
\text { Document review }\end{array}$ \\
\hline
\end{tabular}

\section{The National Patient Survey}

The quantitative analysis builds on data from the National Patient Survey (NPS), which is a regular national survey on patient satisfaction, and is conducted by the Swedish Association of Local Authorities and Regions (see http://npe.skl.se/). The survey has been conducted with primary care healthcare providers since 2009, and specialised hospital care since 2010 . This study uses data from the three NPSs from 2013, 2011 and 2009. The NPS consists of nearly 50 questions that cover the common patient satisfaction dimensions such as interpersonal manner, technical quality, accessibility/convenience, efficacy/outcomes, continuity, physical environment and availability ${ }^{28}{ }^{29}$. For our analysis, we selected, a priori, 23 questions, which were expected to be positively influenced by the Lean implementation based on the results reported in previous research ${ }^{4} 101630$. We excluded, among others, questions on sample taking, medicine prescriptions and promotion of healthy life habits. We categorised the selected questions into five subjects: (A) accessibility and waiting, (B) responsiveness, (C) patient involvement, (D) communication and information sharing, and (E) general impression. Most questions were measured on a five- or three-point Likert scale. The response rates for the NPS, which is sent to randomly selected patients who have recently visited a particular care centre, were 60 percent for 2009 (nearly 165,000 questionnaires sent); 54 percent for 2011 (nearly 248,000 questionnaires sent) and 53 percent for 2013 (nearly 265,000 questionnaires sent). This study builds on a sub-set of this data.

\section{Sample}

The quantitative analysis builds on two sub-samples of care centres that participated in the NPS: one group had been working with Lean healthcare for at least three years (denoted as "Lean group"), and a control group not working with Lean (denoted as "Non-Lean group"). The Lean group was identified in two steps. First, we contacted the county council administrators responsible for primary care to ascertain names of centres working with Lean. Second, we sent out a questionnaire to managers of these centres to examine the extent to which Lean healthcare was applied. The questionnaire consisted of one question about when Lean began and 37 questions on different aspects of its application. The questionnaire was distributed via email to 103 managers, and we received 60 completed responses, that is, a final response rate of about 58 percent. 
To increase the validity of the study, we made a further selection of care centres to include only more mature implementations in the Lean group. The criterion for inclusion was that the primary care centres had been working with Lean for at least three years. We conducted a statistical analysis (independent samples t-test) on the differences between primary care centres working with Lean for at least three years and less than three years, and we found differences in the implementation level. For this reason, we decided to include only 23 primary care centres in the Lean group. An equal number of centres were selected among care centres that had not worked with Lean (Non-Lean group). To ensure the premises in both groups were as similar as possible, we selected care centres from the same county councils and municipalities. Data from 2009, 2011 and 2013 were analysed, with each set including between 2,400-2,800 individual patient responses.

\section{Statistical analysis}

We conducted an independent samples t-test to investigate whether patient satisfaction is significantly different between the Lean and Non-Lean group. Further, we conducted a paired samples t-test to identify differences in patient satisfaction over time $(2009,2011$ and 2013) for the Lean and the Non-Lean group. Tests were selected depending on the parametric assumptions and statistical distributions of the variables. Statistical distribution was assessed by the Shapiro-Wilk test for normality, as well as by the skewness $($ skew $<|2.0|)$ and kurtosis (kurtosis $<|9.0|$ ). ${ }^{31}$ Additionally, the assumption of variance homogeneity was tested via Levene's F test and the effect size was calculated with the Cohen's $d .^{32}$

\section{RESULTS}

In the following section, we present results from case studies and from the analysis of NPS survey data.

\section{Practices of Lean healthcare}

The case studies focused on how the primary care centres defined value from the patient's perspective; how they analysed the value-adding and non-value-adding activities; and what Lean tools and methods have been used to achieve improvements.

One of the challenges in defining value from the patient's perspective in the case organisations was that the patient was considered as one of many customers of healthcare services. When the respondents were asked who their customer was, the first answer was always "the patient". It was commonly stated:

"without patients, healthcare would not be needed" (Nurse, Beta).

After this statement followed reflections like:

"the patient is not a customer in a market economy sense and there are other customers that also need to be considered, that is, family members, other healthcare providers, policy makers and citizens" (Physician, Beta)

"the physician can also be a customer since he or she can be the person needing to be satisfied in the next process step" (Care centre manager, Alpha)

Different value perspectives emerged in the interviews depending on who was considered a customer, such as productivity gains, improved working conditions or more care access. For instance, one physician at Alpha stressed the results in terms of improved productivity and working conditions: "We produced more visits in March than ever previously". Asked how the extra capacity was used, he said that: "we still work overtime; the goal is to work normal hours". The healthcare staff explained that value cannot be defined 
solely by patients, but needs also to consider the perspective of all the key customers including health care professionals in order to ensure quality, safety and appropriate service.

In the studied cases, patients were rarely used as a direct source of information for defining value, although the mandatory patient survey and complaints were mentioned. The usual practice was to focus on eliminating waste from processes from the staff perspective. One of the physicians argued that these may in turn translate into improved value from a patient's perspective:

"I think that most of the patients that come here feel they've come to a harmonious workplace [...] and that we actually work in teams for them" (Physician, Alpha)

Both case organisations used VSM to eliminate waste. The method implied mapping the sequence of activities, with some value streams mapping the patient flow, and others mapping the staff or information flow. The manager of Alpha explained:

"the idea is to view this as production lines at [a car manufacturer] and that a group leader has a number of lines that he can follow along and see the value flows in the different stations - are there wastes and how do we solve it?" (Care centre manager, Alpha)

One example of mapping patient flow was the registration and physician appointment process where a cross-professional team mapped what happens from the moment the patient calls to make an appointment until he or she receives the care needed. When all steps had been mapped, the team identified disturbances, duplicate work, waiting and delays. An example of an identified problem was that telephone queues are particularly long on Mondays. Further investigation revealed that patient demand for care was higher at the beginning of the week, while healthcare staff availability was lower since physicians tended to plan their "appointment-free days" on Mondays. Understanding this fact led to the implementation of several changes, which improved telephone availability and decreased wait times for physician appointments at both care centres.

Another type of VSM was conducted from the staff perspective, and considered other healthcare providers or the staff itself as customers. A physician at healthcare centre Beta describes the approach:

"it is important to identify that there are flows and processes, and to make it as simple as possible, to do the right thing at the right time in the right way. Lean is very much about structure” (Physician, Beta)

An example of this type of VSM was the referral process at Care Centre Beta. VSM was used to map the activities carried out by staff to book appointments with specialists. The goal was to process referrals more quickly, without negatively influencing safety. As a result, a new referral process was developed in which patients were referred only electronically, thereby completely abandoning the parallel paper process.

Although the healthcare staff stated that VSM is meant to improve value from the patient's perspective, no patients were involved in any of the VSMs undertaken, nor were methods applied to understand or determine what the patients required, expected or desired in terms of value.

In addition to VSM, several other Lean tools and methods were implemented at the case organisations. These included $5 \mathrm{~S}$, system for continuous improvement, visualisation of performance data and standardised work. For example, Care Centre Beta introduced 5S and a standardised treatment trolley in physicians' rooms. The benefit of this was that physicians could use any available room to examine patients, did not spend time on unnecessary searching, and could pass the responsibility for organising and refilling the treatment trolleys to other staff. Another example related to the organisation of daily improvement work. Both 
care centres developed systems for capturing and implementing staff ideas. The majority of improvements focused on eliminating daily problems and reducing waiting and delays both for those who receive and those who give care. Providing timely care was an important principle characterising Lean healthcare at the case organisations. The results included increased availability by phone, shorter waiting time to get a doctor's appointment, increased patient throughput, decreased stress and improved staff satisfaction.

\section{Analysis of patient satisfaction}

In this section, we describe the results from the statistical analysis of patient satisfaction based on data from the NPS.

Table II presents the mean values and significance levels from t-tests for the selected 23 questions on accessibility and waiting (A1-A5), responsiveness (B1-B5), patient involvement (C1-C5), communication and information sharing (D1-D5), and general impression (E1-E3). The mean values for the respective group (Lean/Non-Lean) were calculated from scores of each primary care centre. Data from 2009, 2011 and 2013 is presented. Standard deviations did not exceed 0.8 for questions on the five-point Likert scale, or 0.3 on the three-point Likert scale.

\section{Lean group compared to Non-Lean group}

In 2009, no significant differences were found between the Lean group and the Non-Lean group for any of the selected questions.

In 2011, two significant differences were found. First, the patients of the Lean group were less satisfied with physicians listening to what patients had to say than the patients of the Non-Lean group (question C3 in Table II), $\mathrm{t}(46)=2.002, \mathrm{p}<.05$. Cohen's $d$ was estimated at 0.6 , which is a medium effect based on the guidelines. Second, patients of the Lean group were less satisfied with physicians paying sufficient attention to patient experience of the illness than the patients of the Non-Lean group (question C4 in Table II), $\mathrm{t}(46)=2.078, \mathrm{p}<.05$, demonstrating a medium effect size, $\mathrm{d}=0.7$.

In 2013, no significant differences were found on any of the selected questions.

\section{Development over time for Lean group}

In the next step, we conducted a paired samples t-test to examine changes in patient satisfaction over time. For the Lean group, eight significant differences over the years were found (see Table II). Between the years 2009 and 2011 significant differences were found for question D4: $\mathrm{t}(22)=2,071, \mathrm{p}<.05$ and question D5: $\mathrm{t}(22)=2,070, \mathrm{p}<.05$. Between the years 2009 and 2013 significant differences were found for questions A3: $\mathrm{t}(22)=3,003, \mathrm{p}<.01 ; \mathrm{C} 2$ : $\mathrm{t}(22)=2,592, \mathrm{p}<.01 ; \mathrm{D} 1: \mathrm{t}(22)=2,158, \mathrm{p}<.05 ; \mathrm{D} 2: \mathrm{t}(22)=2,863, \mathrm{p}<.05 ; \mathrm{D} 4: \mathrm{t}(22)=2,237$, $\mathrm{p}<.05$ and $\mathrm{E} 2: \mathrm{t}(22)=\mathrm{t}(22)=2,345, \mathrm{p}<.03$. All the significant differences implied a decrease in patient satisfaction. It should be noted that four of seven questions were related to communicating and providing information to patients (subgroup D).

\section{Development over time for Non-Lean group}

For the Non-Lean group, one significant difference was found between the years 2009 and 2011 for the question B1. The Non-Lean group significantly improved regarding informing patients about appointment delay, $\mathrm{t}(23)=2,118, \mathrm{p}<.05$. Since we had the data available for all primary care centres in Sweden, we also tested the whole sample for differences between years. No significant differences were found for any of the selected survey questions. 
Table II: Mean values and significance levels for t-tests for 23 questions selected from the NPS

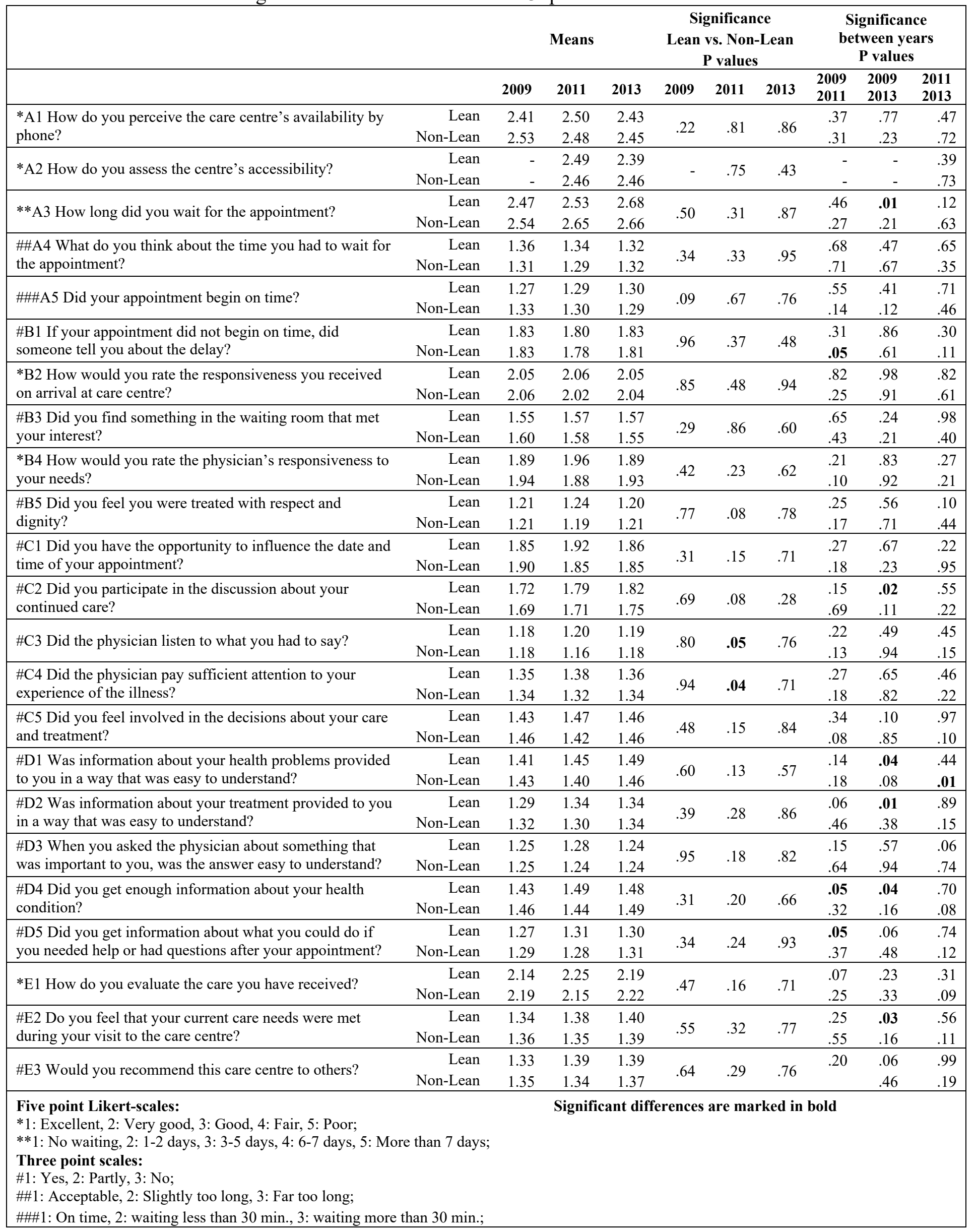




\section{DISCUSSION AND IMPLICATIONS}

\section{Influence on patient satisfaction}

One of the most commonly repeated reasons for why Lean production is valuable for healthcare is the way it focuses on creating value for the customer.$^{5-8}$ Despite the associated rhetoric, our findings indicate that patients of Lean primary care centres are not more satisfied than patients of Non-Lean centres. Instead, the results suggest a negative development over time for the Lean primary care centres. A small but statistically significant decrease in patient satisfaction over years vis-à-vis the quality of information and communication during the patient-physician meeting was found. Could this negative development on patient satisfaction be motivated and explained by the improvement of patient throughput frequently cited in Lean case studies? ${ }^{33-35}$ A possible explanation is that physicians have less time to spend with patients, which is noticed by patients. The patient-physician meeting is the most important occasion to co-create patient value, and also the occasion on which the functional quality of care is evaluated.

Since several case studies indicate that Lean production leads to reduced wait times, ${ }^{10}$ it is surprising that at least the perceived accessibility did not improve but worsened over time for the Lean group. Although not statistically significant, the same negative trend is observed for the Non-Lean group. Further analysis of the whole sample of primary care centres has shown that the perceived waiting time has increased over time. Thus, this fact indicates that the negative development could be attributed to some other factors than Lean.

The significant differences observed should be interpreted cautiously. There are several limitations inherent in the statistical analysis. The mean differences are small and multiple comparisons in t-tests increase the chance of getting Type 1 Error. ${ }^{36}$ An even distribution of response scale is difficult to achieve in research on patient satisfaction and the distribution of means tends to be positively skewed. ${ }^{37}$ There is a potential problem with ceiling effects, which imply that the distribution of scores is artificially limited at the lower end of the scale and there is no sufficient room to measure the improvement below the mean. Further, although we made a careful selection of primary care centres for the Lean group, we have a limited knowledge about the care centres themselves and how they operationalised the Lean principles. While care centres in Sweden have similar legal and financial premises, they may differ on aspects such as organisational culture and leadership. This might imply that the differences observed between Lean and Non-Lean care centres and over time are not attributable to Lean. Another limitation is the time frame of the study. The primary care centres selected for the Lean group were supposed to work with Lean for at least three years. The question is whether the time frame is enough to observe improvements in the patient satisfaction.

\section{Defining value in Lean healthcare}

The purpose of the case studies was to explore the practices of defining and improving value from the patient's perspective. The findings provide some insights for why the implementation of Lean healthcare in primary care centres may not lead to improved patient satisfaction. Since only two cases in a Swedish context were studied, the results might be biased by the choice of the case organisations. It should be noticed, however, that the selected primary care centres are considered as initial and successful cases of Lean healthcare implementation in Sweden. The case organisations were found not to involve patients in the process of defining value, and to have undertaken very few activities with the deliberate purpose of improving patient satisfaction. Radnor et al. ${ }^{16}$ reported similar results, showing 
that the Lean applications in healthcare tend towards a tool-based approach for operational problems, with little attention paid to defining value from the patient's perspective.

While this sharply contrasts with the evolved standpoint in the service literature ${ }^{1921}$, it must be noted that value is a more complex construct in healthcare than in other settings. Whereas customers in other contexts may have the ability to determine the value they experience, this is far from the case in the healthcare context. Although patients can perceive the value of healing or being treated with respect, the nature of healthcare is such that good care does not always produce good health outcomes- and vice versa. Further, healthcare providers need to consider multiple stakeholders and do not know whether they should work towards the value defined by individual patients, healthcare professionals, local councils commissioning care services, or indeed the government. ${ }^{16}$ In our view, value must be codefined by patients, who have their own preferences and experiential needs (functional quality), and by professionals, who can tell whether treatment is in line with latest evidence (technical quality).

\section{Patient involvement and the future of Lean healthcare}

Lean production originally stems from a goods-dominant logic (GDL), where value vis-à-vis healthcare is assumed to be primarily created in the provider's sphere. ${ }^{21}$ From the GDL perspective, the provider and patient spheres interact only to a very limited extent. In Lean healthcare improving value frequently implies evaluating all activities, whether they add or not, and identifying waste. ${ }^{8} 10$ The case organisations focused primarily on their own activities, while the patient's role in the value-creation process was not given much consideration. This is not surprising, since Lean production was originally designed to improve the efficiency of a production system. According to GDL, the experiential and contextual aspects of value remain unseen; primarily technical, rather than functional, value is acknowledged. Consequently, as value is seen to be created by the healthcare provider, the patient sphere is not seen as an arena for value creation and is thus overlooked.

It has been suggested that service improvements may be carried out from either an inside-out or an outside-in perspective. ${ }^{38}$ The former stresses efficiency of services and development through the lens of the organisation, while the latter views the service through the lens of the customer and focuses on its effectiveness. ${ }^{39}$ This study confirms previous findings ${ }^{16}$ that Lean production is applied using an inside-out perspective, where the healthcare staff defines value for the patient based on the organisation's lens. This implies that service improvements are being undertaken without actually understanding the patient's perspective. Therefore, an important Lean strategy is to develop systematic approaches to defining value that integrate both the knowledge and clinical expertise of healthcare providers, and the patients' preferences and needs. The service management literature offers a wide range of methodologies, such as focus groups, diaries and patient blogs, that can be used in the context of patient value co-creation. ${ }^{40}$

\section{CONCLUSIONS}

The underlying principle of Lean is to define value from the customer's perspective. Although the literature suggests that Lean healthcare helps to improve patient satisfaction, our study shows that patients of care centres working with Lean are not more satisfied than patients of care centres not working with Lean. These results may point to important limitations in how Lean healthcare is operationalised today and calls for the development of patient-centric practices in Lean.

While Lean production has demonstrated valuable contributions to more timely and efficient healthcare, it may have a limited impact on patient satisfaction as it lacks tools and methods 
that enhance customer participation in the value-creation process. This might be one of the reasons why Lean healthcare initiatives primarily target internal efficiency, and do not focus on activities to improve patient satisfaction. In order to achieve not only more timely and efficient care, but also more patient-centred care, the patient's perspective needs to be better integrated in current Lean healthcare applications; for instance, by actively involving patients in activities such as defining value, and in value stream mapping.

\section{REFERENCES}

1 Fullerton RR, McWatters CS, Fawson C. An examination of the relationships between JIT and financial performance. J Oper Manag 2003;21(4):383-404.

2 de Souza L. Trends and approaches in lean healthcare. Leadersh Health Serv 2009;22(2):121-39.

3 Andersen H, Røvik KA, Ingebrigtsen T. Lean thinking in hospitals: is there a cure for the absence of evidence? A systematic review of reviews. BMJ open Published Online First: 15 January 2014. doi:10.1136/bmjopen-2013-003873.

4 Mazzocato P, Savage C, Brommels M, Aronsson H, Thor J. Lean thinking in healthcare: a realist review of the literature. Qual Saf Health Care 2010;19(5):376-82.

5 Kenney C. Transforming health care: Virginia Mason Medical Center's pursuit of the perfect patient experience. New York: Productivity Press, 2010.

6 Fillingham D. Lean healthcare: improving the patient's experience. 1st edition ed. Chichester: Kingsham Press, 2008.

7 Wellman J, Jeffries H, Hagan P. Leading the lean healthcare journey: driving culture change to increase value. New York: Productivity Press, 2010.

8 Graban M. Lean Hospitals: Improving Quality, Patient Safety, and Employee Satisfaction. Boca Raton: Productivity Press, 2008.

9 Young T, McClean S. A critical look at Lean Thinking in healthcare. Qual Saf Health Care 2008;17(5):382-86.

10 Poksinska B. The current state of Lean implementation in healthcare - literature review. Qual Manag Health Care 2010;19(4):319-29.

11 Krafcik J. Triumph of the Lean Production System. Sloan Manage Rev 1988;30(1):41-52.

12 Womack J, Jones D. Lean Thinking: Banish Waste and Create Wealth in Your Corporation. New York: Simon \& Schuster, 1996.

13 Kaplan GS, Patterson SH, Ching JM, Blackmore CC. Why Lean doesn't work for everyone. BMJ Qual Saf Published Online First: 23 July 2014. doi:10.1136/bmjqs2014-003248.

14 Towne J. Going 'lean' streamlines processes, empowers staff and enhances care. Hosp Health Netw 2006;80(10):34-25.

15 Ben-Tovim D, Bassham J, Bennett D, et al. Redesigning care at the Flinders Medical Centre: Clinical process redesign using 'lean thinking'. Med J Aust 2008;188(6):27-31.

16 Radnor ZJ, Holweg M, Waring J. Lean in healthcare: The unfilled promise? Soc Sci Med 2012;74(3):364-71.

17 Drotz E, Poksinska B. Lean in Healthcare from Employees' Perspective. J Health Organ Manag 2014;28(2):177 - 95.

18 Spear SJ. Fixing healthcare from the inside: Teaching residents to heal broken delivery processes as they heal sick patients. Acad Med 2006;81(10):144-49.

19 Vargo SL, Lusch RF. Evolving to a new dominant logic for marketing. J Mark 2004;60(1):1-17.

20 Pralahad CK, Ramaswamy V. The future of competition: Co-creating unique value with customers. Boston, Mass: Harvard Business School Press, 2004. 
21 Grönroos C, Ravald A. Service as business logic: implications for value creation and marketing. J Serv Manage 2011;22(1):5-22.

22 Grönroos C. The perceived service quality concept-a mistake? Manag Serv Qual 2001;11(3):150-52.

22a Elg M, Engström J, Witell L, Poksinska B. Co-creation and learning in health-care service development. J Serv Manage 2012;23:328-43.

23 Bodenheimer T, Lorig K, Holman H, et al. Patient self-management of chronic disease in primary care. JAMA 2002;288(19):2469-75.

24 Institute of Medicine. Crossing the Quality Chasm: A New Health System for the 21st Century. Washington: DC: National Academy Press, 2001.

25 Patton MQ. Qualitative research and evaluation methods. Thousand Oaks, CA: Sage Publications, 2002.

26 Kvale S. InterViews. An introduction to Qualitative Research Interviewing. Thousand Oaks, CA: SAGE Publications, 1996.

27 Merriam SB. Qualitative Research and Case Study Applications in Education. Rev. and expanded edition ed. San Francisco: Jossey-Bass, 1998.

28 Ware JE, Snyder MK, Wright WR, et al. Defining and measuring patient satisfaction with medical care. Eval Program Plann 1983;6(3):247-63.

29 Wong ST, Haggerty J. Measuring patient experiences in primary health care: a review and classification of items and scales used in publicly-available questionnaires. Vancouver, BC: Centre for Health Services and Policy Research, University of British Columbia, 2013:1-34.

30 Andersen H, Røvik KA, Ingebrigtsen T. Lean thinking in hospitals: is there a cure for the absence of evidence? A systematic review of reviews. BMJ open 2014;4(1):e003873.

31 Schmider E, Ziegler M, Danay E, et al. Is it really robust? Reinvestigating the robustness of ANOVA against violations of the normal distribution assumption. Methodology 2015;6(4):147-51.

32 Cohen J. Statistical power analysis for the behavioral sciences. New York: Academic press, 2013.

33 Ben-Tovim D, Bassham J, Bolch D, et al. Lean thinking across a hospital: redesigning care at the Flinders Medical Centre. Aust Health Rev 2007;31(1):10-15.

34 Dickson EW, Singh S, Cheung DS, et al. Application of Lean Manufacturing Techniques in the Emergency Department. J Emerg Med 2008;37(2):177-82.

35 Raab SS, Andrew-JaJa C, Condel JL, et al. Improving Papanicolaou test quality and reducing medical errors by using Toyota production system methods. Am J Obstet Gynecol 2006;194(1):57-64.

36 Perneger TV. What's wrong with Bonferroni adjustments. BMJ 1998;316(7139):1236.

37 Garratt A, Bjærtnes ØA, Krogstad U, et al. The OutPatient Experiences Questionnaire (OPEQ): data quality, reliability, and validity in patients attending 52 Norwegian hospitals. Qual Saf Health Care 2005;14(6):433-37.

38 Day GS. The capabilities of market-driven organizations. J Mark 1994;58(4):37-52.

39 Gustafsson A, Johnson M. Competing in a Service Economy: How to Create a Competitive Advantage Through Service Development and Innovation. San Francisco: Jossey-Bass, 2003.

40 Witell L, Kristensson P, Gustafsson A, et al. Idea generation: customer co-creation versus traditional market research techniques. J Serv Manage 2011;22(2):140-59. 